\title{
Produções científicas em cursos de Pós-graduação sobre o rompimento da Barragem de Fundão: perspectivas para o campo educacional
}

\author{
Scientific productions in postgraduate studies about the Fundão's \\ Dam rupture: perspectives for the educational field
}

Producciones científicas en cursos de postgrado sobre el rompimiento de la Presa de Fundão: perspectivas para el campo educacional

Bárbara Oliveira ${ }^{1}$; Carla Mercês da Rocha Jatoba Ferreira²

\section{RESUMO}

O colapso da Barragem de Fundão, no dia 5 de novembro de 2015, foi o maior desastre socioambiental brasileiro e grande parte dos debates sobre o ocorrido se converteram em um conjunto de produções acadêmicas nos programas de pós-graduação em todo o país. Assim, com o objetivo de compreender essas produções, mapeamos os estudos produzidos nas diferentes áreas do conhecimento sobre o desastre e elaboramos 0 estado do conhecimento das teses e dissertações depositadas até o ano de 2019. Nesse contexto, evidenciamos o espaço assumido pelo campo educacional nessas produções acadêmicas. A escassez de alguns estudos indica o foco da preocupação sobre o desastre e demonstra que a discussão é quase totalmente silenciada no campo educacional. Portanto, faz-se necessário fortalecer o campo de estudos acerca dos desastres, bem como pensar estrategicamente sobre como o campo educacional pode contribuir com o debate.

Palavras-chave: Rompimento da Barragem de Fundão; Desastre; Estado do conhecimento; Pesquisas no campo educacional.

\begin{abstract}
The Fundão's dam collapse, on November 5, 2015, was the biggest Brazilian socio-environmental and much of the debate about what happened turned into a set of academic productions in graduate programs across the country. Thus, in order to understand these productions, we mapped the studies produced in the different areas of knowledge about the disaster and elaborated the state of knowledge of the thesis and dissertations placed until 2019. In this context, we highlighted the relevance assumed by the educational field in these academic productions. The shortage of some studies indicates the focus of concern about the disaster and demonstrates that the discussion is almost completely silenced in the educational field. Therefore, it is necessary to strengthen the field of studies about disasters, as well as to think strategically about how the educational field can contribute to the debate.
\end{abstract}

Keywords: Fundão's dam rupture; Disaster; State of knowledge; Educational research.

\section{RESUMEN}

El colapso de la presa de Fundão, el día 5 de noviembre de 2015, fue el mayor desastre socioambiental brasileño y gran parte de los debates sobre lo ocurrido se convirtieron en un conjunto de producciones académicas en los programas de Postgrado en todo el país. Así, con el objetivo de comprender esas producciones, mapeamos los estudios producidos en las diferentes áreas del conocimiento sobre el desastre y elaboramos el estado del conocimiento de las tesis y disertaciones depositadas hasta el año de 2019. En ese contexto, evidenciamos el espacio asumido por el campo educacional en esas producciones académicas. La escasez de algunos estudios

\footnotetext{
${ }^{1}$ Mestranda no Programa de Pós-Graduação em Educação da Universidade Federal de Ouro Preto (UFOP), Ouro Preto/MG - Brasil.

2 Professora do Programa de Pós-Graduação em Educação da Universidade Federal de Ouro Preto (UFOP), Ouro Preto/MG - Brasil.
} 
indican el foco de la preocupación sobre el desastre y demuestra que la discusión es casi totalmente silenciada en el campo educacional. Por tanto, se hace necesario fortalecer el campo de estudios a cerca de los desastres, bien como pensar estratégicamente sobre cómo el campo educacional puede contribuir con el debate.

Palabras clave: Rompimiento de la presa de Fundão; Desastre; Estado del conocimiento; Pesquisas en el campo educacional.

\section{INTRODUÇÃO}

No dia 5 de novembro de 2015, a barragem de rejeitos de minério de ferro de Fundão, pertencente à empresa Samarco e também controlada por duas das maiores mineradoras do mundo - Vale e BHP Billiton - rompeu. O rompimento da barragem se converteu na maior tragédia ambiental brasileira e no mais grave desastre da história da mineração mundial - até aquele momento -, especialmente pelo ineditismo e pela dimensão do acontecimento. Infelizmente, 19 pessoas morreram só na primeira meia hora do evento. Nos dias que se seguiram, a vida de outras centenas de milhares, que viviam ao longo dos 650 quilômetros percorridos pela lama, fora arbitrariamente afetada (DIEGUEZ, 2016).

Assim que a estrutura estourou, a massa engoliu o córrego Fundão e o córrego Santarém até chegar ao rio Gualaxo do Norte. O rio determinou o rumo da lama e tudo que estava nas margens foram sendo destruídos. A lama prosseguiu para o rio do Carmo até o encontro com o rio Piranga - da confluência dos dois nasce o rio Doce - e seguiu pelo o rio Doce até o oceano. A lama tóxica destruiu toda a vida do ecossistema pela qual ela percorreu (SERRA, 2018). O cenário completamente devastado de dois povoados e dezenas de outras comunidades atingidas refletem a dimensão dos impactos socioambientais do desastre.

A discussão do fenômeno é um campo relativamente novo no Brasil. Segundo Marchezini (2018), percebe-se o crescimento de dissertações, teses e grupos de pesquisas somente quando há desastres de repercussão nacional. Além disso, a temática do desastre tem passado a ser estudada em maior variedade nos campos disciplinares, porém ainda há concentração de áreas que detém de forma mais consolidada essa discussão.

O colapso da Barragem de Fundão em 2015 inaugurou um novo ciclo de debates sobre o modelo econômico, a crise ecológica e as decorrentes consequências às comunidades atingidas e aos danos ao meio ambiente. Os debates se converteram em um conjunto de produções acadêmicas nos programas de pós-graduação do Brasil. Assim, para compreender essas produções, elaboramos o estado do conhecimento no presente artigo, isto é, realizamos um processo de análise qualitativa descritivo e analítico - para mapear os estudos produzidos nas diferentes áreas do conhecimento sobre o evento e, por fim, discutirmos a dimensão do campo educacional nas respectivas produções.

Além disso, o rompimento da barragem do Córrego do Feijão, em Brumadinho (2019), reafirmou a necessidade da urgência da discussão sobre a mineração e seus impactos. Segundo Rezende e Silva (2019), o maior ponto de convergência entre os dois desastres é que em ambos os casos pode-se identificar a responsabilidade da empresa Vale, pois, as controladoras da Samarco à época do ocorrido eram a Anglo-Australiana BHP Billiton e a brasileira Vale S/A, que no ano de 2019 rompe novamente uma de suas barragens. Assim, Rezende e Silva (2019) afirmam que é imperioso reconhecer o envolvimento direto da Vale em ambas as catástrofes e que a ocorrência do segundo desastre, demonstra que não houve por parte da empresa um aprendizado que resultasse na mudança de postura em relação a segurança de suas barragens, proteção ambiental e respeito à vida. 
O estudo do desastre na perspectiva sociológica deve necessariamente, de acordo com Valencio (2009), focalizar na estrutura e na dinâmica social, a partir das interpretações acerca das relações sociais territorial, institucional e historicamente produzida. Conforme Valencio (2009), o desastre é um fenômeno social de constatação pública, na qual caracteriza-se pela vulnerabilidade na relação do Estado com a sociedade, uma vez que o Estado não conseguiu impedir ou minorar os danos diante de uma ameaça. Isto é, trata-se

De um indicador de falha no cumprimento do contrato social relativo à organização e administração público do espaço das relações econômicas e extraeconômicas territorializadas, o que fere dimensões de confiança no ente público que, às duras penas, precisará repactuar a convivência dos sujeitos em bases mais precárias (VALENCIO, 2009, p.6).

Assim, com o objetivo de compreender o estado do conhecimento foi realizada o levantamento no Banco de Teses e Dissertações da Coordenação de Aperfeiçoamento de Pessoal de Nível Superior (Capes) e na Biblioteca Digital Brasileira de Teses e Dissertações (BDTD-IBICT). O critério para a seleção do material que compõe o corpus do estado do conhecimento se deu a partir o descritor: rompimento da barragem de Fundão. Com o intuito de localizar toda a produção nesses bancos, não houve recorte temporal.

Dessa forma, a primeira parte do artigo referente aos dados, a partir do descritor citado, resultou na compilação de 81 trabalhos acadêmicos, abrangendo todas as áreas de pesquisas acadêmicas sobre o rompimento da barragem de rejeitos de mineração das empresas Samarco/Vale/BHP Billiton. Na segunda parte, apresentamos três dissertações que integram discussões relevantes para o campo educacional.

\section{METODOLOGIA}

O artigo reafirma a importância de trabalhos denominados estado do conhecimento em que se propõe investigar o panorama do conhecimento produzido pelas universidades, faculdades e centros educacionais no Brasil e no mundo, de acordo com os critérios de seleção, para a reflexão das contribuições e os limites das pesquisas acadêmicas, sendo este meio necessário "no processo de evolução da ciência, a fim de que se ordene periodicamente o conjunto de informações e resultados já obtidos" (SOARES, 1987 apud FERREIRA, 2002, p. 259). Além disso, as lacunas apresentadas pelos estados do conhecimento ou estado da arte de modo geral podem e devem estimular e justificar as futuras pesquisas sobre os temas investigados.

Ao utilizar o descritor rompimento da barragem de fundão no Banco de Teses e Dissertações da Capes no mês de outubro de 2019, apareceram 17 resultados. Porém, consideramos que o número não contempla a realidade das produções. Portanto, foi necessário buscar outro método que abrangesse o máximo de trabalhos presentes na plataforma. Assim, utilizou-se outro descritor, acrescentando uma letra maiúscula rompimento da barragem de Fundão. Com esse descritor, foram encontrados 50 resultados.

O objetivo de buscar o máximo de trabalhos produzidos que contemplam a temática deve-se à tentativa de fazer o balanço de todas as teses e dissertações produzidas sobre o desastre de 2015. Quando utilizada a barra de ferramentas para filtragem, foram constatados 63 autores(as) que tiveram suas produções relacionadas à temática. Ao lista-los, tivemos a relação daqueles que ainda não constavam nas primeiras buscas. Além disso, ao pesquisar na Biblioteca Digital Brasileira de 
Teses e Dissertações com o mesmo descritor, encontramos, inicialmente, 32 resultados, no dia 23 de dezembro de 2019. Desses, 16 pesquisas não estavam anexadas na plataforma da Capes, estas que foram, posteriormente, acrescentadas ao levantamento. Assim, a partir dessas etapas individuais, utilizou-se a união de todas as buscas para a realização do estado do conhecimento das pesquisas com a temática do rompimento da Barragem de Fundão, no Brasil, nas plataformas da Capes e da BDTD-IBICT até 2019. Os dados utilizados referem-se à união de todas as etapas descritas anteriormente.

A realização desse levantamento possibilita organizar e analisar, segundo Romanowski e Ens (2006, p. 39), "na definição de um campo, uma área, além de indicar possíveis contribuições da pesquisa para com as rupturas sociais". Dessa forma, a multiplicidade e a pluralidade de perspectivas abordadas pelas pesquisas acadêmicas acerca do desastre em Mariana contribuem para 0 entendimento de tal fenômeno e dos inúmeros efeitos causados à sociedade brasileira. Assim, com o intuito de mapear e discutir uma certa produção acadêmica, em um período delimitado, em anos, locais e áreas de produção, traçamos um dos possíveis estados do conhecimento acerca do desastre.

Segundo Ferreira (2002), a pesquisa denominada estado do conhecimento possui o caráter bibliográfico ao se interessar pelas produções realizadas na esfera acadêmica, isto é, busca avaliar o conhecimento sobre o tema e compreender a dimensão de tal conhecimento. Portanto, permite-nos traçar os lócus de investigação que foi dado a tal fenômeno social bem como as limitações e lacunas das pesquisas acadêmicas ao tratar a problemática instaurada, ilustrada também pela escassez de trabalhos provenientes em alguns programas de pós-graduação que serão descritos a seguir.

\section{RESULTADOS E DISCUSSÃO}

As informações apresentadas neste artigo representam o panorama da produção de teses e dissertações relacionadas ao tema até a data de 31 de dezembro de 2019, somando 72 dissertações e nove teses nas diferentes áreas de conhecimentos, ou seja, sem filtro de área. Dessa forma, foram lidos os 81 resumos, agrupados em categorias e citados nas respectivas tabelas, sendo a Tabela 10 ano de produção das pesquisas acadêmicas; a Tabela 2, as instituições de produção dos trabalhos por estado/região; e a Tabela 3, os programas de pós-graduação por grande área, segundo os critérios da CAPES.

\subsection{0 rompimento da barragem de fundão nas pesquisas acadêmicas}

Tabela 1 - Número de teses e dissertações sobre o rompimento da Barragem de Fundão publicadas até dezembro de 2019

\begin{tabular}{c|c|c|c|c|c}
\multirow{2}{*}{ Descritor } & \multicolumn{5}{|c}{ Números de teses e dissertações } \\
\cline { 2 - 6 } & 2016 & 2017 & 2018 & 2019 & Total \\
\hline $\begin{array}{c}\text { Rompimento da } \\
\text { barragem de Fundão }\end{array}$ & 2 & 19 & 44 & 16 & 81
\end{tabular}

Fonte: Elaboração própria a partir de dados da BDTD-IBICT e do Banco de Teses e Dissertações da Capes (2019). 
Observando a Tabela 1, verificamos que a produção foi relativamente baixa em 2016, tendo apenas duas dissertações: a primeira, com foco no acontecimento histórico ao estudo discursivo de charges, em um programa de Letras; e a segunda, sobre a qualidade das águas nos rios Gualaxo do Norte, Gualaxo do Sul e do Carmo e afluentes do Alto do Rio Doce, em um programa de Engenharia Ambiental.

Em 2017, os trabalhos se ampliaram na discussão sobre as diferentes perspectivas da problemática. Das 19 pesquisas produzidas, havia apenas uma tese em um programa de pós-graduação em Serviço Social e seis dissertações na área do Direito.

Em 2018, as pesquisas aumentaram consideravelmente, contabilizando 38 dissertações e seis teses. Assim, sendo o ano que apresentou mais trabalhos acadêmicos, foi também quando os trabalhos apresentaram maior variedade de produção por programas de pós-graduação, perpassando, principalmente, pelas áreas da Economia, Direito e Administração. Além disso, 2018 apresentou o maior número de teses de doutorado.

Segundo Oliveira (2019), o rompimento da Barragem do Fundão se tornou o primeiro crime ambiental brasileiro classificado como violação de direitos humanos por parte do Conselho Nacional de Direitos Humanos (CNDH). Entretanto, essa classificação só foi emitida em dezembro de 2019, ano em que as pesquisas estavam discutindo o desastre socioambiental, principalmente nos programas de pósgraduação em Direito.

A Tabela 2 apresenta os locais de produção desses trabalhos a partir de estados e regiões do país. 0 levantamento revelou que a Universidade Federal de Viçosa (UFV) se destacou por apresentar 10 dos trabalhos levantados.

Tabela 2 - Instituições de produção das teses e dissertações por estado/região sobre o rompimento da Barragem de Fundão publicadas até dezembro de 2019

Número de pesquisas

Minas Gerais

\begin{tabular}{c|c}
\hline Universidade Federal de Viçosa & 10 \\
\hline Universidade Federal de Ouro Preto & 9 \\
\hline Universidade Federal de Minas Gerais & 8 \\
\hline Universidade Federal de Lavras & 3 \\
\hline Universidade Vale do Rio Doce & 3 \\
\hline Universidade Federal de Juiz de Fora & 3 \\
\hline Centro Federal de Educação Tecn. de Minas Gerais & 1 \\
\hline Universidade Federal de Uberlândia & 1 \\
\hline Pontifícia Universidade Católica de Minas Gerais & 1 \\
\hline Universidade Fumec & 1 \\
\hline Centro Universitário Una & 1 \\
\hline Escola Superior Dom Helder Câmara & 1 \\
\hline Total & 42 \\
\hline
\end{tabular}

\section{Rio de Janeiro}

Universidade do Estado do Rio de Janeiro

Fundação Oswaldo Cruz

1




\begin{tabular}{|c|c|}
\hline Instituto de Radioproteção e Dosimetria & 1 \\
\hline Universidade Federal do Estado do Rio de Janeiro & 1 \\
\hline Universidade Federal do Rio de Janeiro & 1 \\
\hline Universidade Federal Rural do Rio de Janeiro & 1 \\
\hline Universidade Federal Fluminense & 1 \\
\hline Total & 10 \\
\hline \multicolumn{2}{|l|}{ Espírito Santo } \\
\hline Universidade Federal do Espírito Santo & 6 \\
\hline Universidade de Vila Velha & 2 \\
\hline Faculdade de Direito de Vitória & 1 \\
\hline Total & 9 \\
\hline \multicolumn{2}{|l|}{ São Paulo } \\
\hline Universidade Estadual Paulista & 2 \\
\hline Universidade Anhembi Morumbi & 1 \\
\hline Universidade de São Paulo & 1 \\
\hline Pontifícia Universidade de São Paulo & 1 \\
\hline Total & 5 \\
\hline \multicolumn{2}{|l|}{ Distrito Federal } \\
\hline Universidade de Brasília & 4 \\
\hline Centro Universitário do Distrito Federal & 1 \\
\hline Total & 5 \\
\hline \multicolumn{2}{|l|}{ Região Sul } \\
\hline Universidade Federal de Santa Catarina & 2 \\
\hline Universidade Federal do Paraná & 1 \\
\hline Universidade Católica de Pelotas & 1 \\
\hline Universidade Federal de Santa Maria & 1 \\
\hline Universidade Caxias do Sul & 1 \\
\hline Faculdade Meridional & 1 \\
\hline Total & 7 \\
\hline \multicolumn{2}{|l|}{ Região Nordeste } \\
\hline Universidade Católica de Salvador & 2 \\
\hline Universidade Federal do Ceará & 1 \\
\hline Total & 3 \\
\hline
\end{tabular}

Fonte: Elaboração própria a partir de dados da BDTD-IBICT e do Banco de Teses e Dissertações da Capes (2019).

De acordo com a Tabela 2, é possível perceber a concentração dessas pesquisas na Região Sudeste do país, com 66 trabalhos. Portanto, essa região foi desmembrada em estados para identificar que Minas Gerais, o estado mais afetado pelo desastre, também foi o que mais produziu pesquisas a respeito, contabilizando 42 trabalhos. O número de produções, intensificou-se em três instituições: Universidade Federal de Viçosa (UFV), Universidade Federal de Ouro Preto (UFOP) e Universidade Federal de Minas Gerais (UFMG), com 10, 9 e 8 trabalhos, respectivamente.

A primeira universidade se destaca com a maior produção de pesquisas nos programas de Agronomia e Microbiologia Agrícola. A segunda tem seu destaque nas produções, primeiramente, por estar no 
epicentro do desastre, onde os desdobramentos foram sentidos em diversos âmbitos, alterando de diversas formas a vida dos sujeitos residentes da região de Ouro Preto, Mariana e seus distritos. A terceira universidade possui uma produção variada de pesquisas nos programas de Ambiente Construído e Patrimônio Sustentável, Biologia Vegetal, Sociologia e Arquitetura e Urbanismo.

O segundo estado mais afetado pelo rompimento da barragem aparece com a terceira maior produção de pesquisas, sendo este o Espírito Santo, como descrito na Tabela 2. É importante levar em consideração que não foram afetados apenas os estados de Minas Gerais e Espírito Santo; o país por completo presenciou e presencia o reflexo de um desastre de tamanha magnitude. De acordo com as matérias do G1 (2016) e da National Geographic Brasil (2019), alguns estudos apontam que a lama toxica, através do oceano Atlântico, chegou comunidades recifais do sul da Bahia, por exemplo. Além disso, percebe-se também que o sentimento de insegurança em relação as barragens, após esse episódio, passaram a ser presente na vida de muitos brasileiros. Portanto, se pensarmos o meio ambiente enquanto biosfera, sendo um conjunto de todas as partes interligadas do planeta onde existe ou pode existir vida a afetação do desastre torna-se é impossível quantificar. No entanto, é evidente a concentração das pesquisas no estado de Minas Gerais, ponto de origem e estado mais afetado pelo desastre.

Além disso, a Região Sul também apresenta relativa produção sobre o rompimento da Barragem de Fundão, sendo que o estado do Rio Grande do Sul ganha destaque com quatro trabalhos produzidos neste período. Na Tabela 2, outro dado que chama a atenção é o fato de que não há nenhum trabalho produzido no Norte nem no Centro-oeste do país, com exceção do Distrito Federal, que apresentou cinco trabalhos sobre o assunto.

Ao realizar o levantamento das pesquisas, a relação da produção por programas de pós-graduação também nos revela dados importantes para a discussão. Para a produção da Tabela 3, as pesquisas foram agrupadas em três eixos. De acordo com as grandes áreas estabelecidas pela CAPES, aglutinamos em eixos as áreas que, em geral, correspondem um maior grau de proximidade: o primeiro eixo, diz respeito às pesquisas relacionadas às três grandes áreas das Ciências Humanas, Ciência Sociais Aplicadas e Linguística, Letras e Artes; o segundo eixo é referente a grande área Multidisciplinar; o terceiro eixo é representado pelas quatro grandes áreas da Ciência Exatas e da Terra, Ciências Biológicas, Engenharias e Ciências da Saúde.

As teses e dissertações foram agrupadas de forma a incorporar o maior número de trabalhos por programa. Dessa forma, alguns programas perderam características específicas, como, por exemplo, em relação ao Direito: foram encontrados trabalhos em direito, direitos ambientais, direitos humanos, direitos e instituições democráticas, porém, para facilitar a observação e identificação, foram todos resumidos na categoria Direito. Assim, a distribuição das pesquisas em relação aos programas nos quais estão inseridas, de acordo com as grandes áreas estabelecidas pela CAPES, é apresentado na Tabela 3.

\section{Tabela 3 - Teses e dissertações sobre o rompimento da Barragem de Fundão nos Programas de Pós-Graduação/Eixo publicadas até dezembro de 2019}

\begin{tabular}{c|c} 
Eixo I - Ciências Humanas, Ciência Sociais Aplicadas e & $\begin{array}{c}\text { Número de } \\
\text { pesquisas }\end{array}$ \\
\hline Linguística, Letras e Artes & 10 \\
\hline Direito & 5 \\
\hline Economia & 4
\end{tabular}




\begin{tabular}{|c|c|}
\hline Ciências Sociais & 4 \\
\hline Serviço Social & 3 \\
\hline Geografia & 3 \\
\hline Administração & 3 \\
\hline Arquitetura e Urbanismo & 2 \\
\hline Educação & 2 \\
\hline Comunicação Social & 2 \\
\hline Ciências Contábeis & 1 \\
\hline Psicologia social & 1 \\
\hline Ambiente construído e Patrimônio sustentável & 1 \\
\hline Gestão para a Competitividade & 1 \\
\hline Total & 42 \\
\hline Eixo II - Multidisciplinar & $\begin{array}{l}\text { Número de } \\
\text { pesquisas }\end{array}$ \\
\hline Desenvolvimento sustentável & 1 \\
\hline Total & 1 \\
\hline $\begin{array}{c}\text { Eixo III - Ciência Exatas e da Terra, Ciências Biológicas, } \\
\text { Engenharias e Ciências da Saúde }\end{array}$ & $\begin{array}{l}\text { Número de } \\
\text { pesquisas }\end{array}$ \\
\hline Saúde coletiva & 3 \\
\hline Engenharias & 5 \\
\hline Ciência do Solo & 4 \\
\hline Biologia Vegetal & 4 \\
\hline Gestão Integrada do Território & 3 \\
\hline Agronomia & 3 \\
\hline Microbiologia Agrícola & 3 \\
\hline Ecologia de Ecossistemas & 2 \\
\hline Planejamento Ambiental & 2 \\
\hline Radioproteção e Dosimetria & 1 \\
\hline Produção vegetal & 1 \\
\hline Ciências Ambientais e Florestais & 1 \\
\hline Entomologia & 1 \\
\hline Hospitalidade & 1 \\
\hline Geociência (Geoquímica) & 1 \\
\hline Botânica & 1 \\
\hline Ciência Farmacêuticas & 1 \\
\hline Química & 1 \\
\hline Total & 38 \\
\hline
\end{tabular}

Fonte: Elaboração própria a partir de dados da BDTD-IBICT e do Banco de Teses e Dissertações da Capes (2019).

De acordo com a Tabela 3, a produção das pesquisas se deu de maneira diversificada nos programas de pós-graduação. Inicialmente, a hipótese era de que a concentração de trabalhos nas grandes áreas das Ciências Humanas, Ciência Sociais Aplicadas e Linguística, Letras e Artes seria relativamente menor em comparação ao número encontrado no levantamento. A proporção relativa do Eixo I (Ciências Humanas, Ciência Sociais Aplicadas e Linguística, Letras e Artes) em comparação ao Eixo 
III (Ciência Exatas e da Terra, Ciências Biológicas, Engenharias e Ciências da Saúde) deve-se, principalmente, à alta produção de pesquisas relacionadas aos programas de pós-graduação em Direito, com a maior produção de pesquisas sobre o rompimento da Barragem de Fundão. Porém, nos programas de pós-graduação em Educação, há apenas uma dissertação produzida na Universidade Federal do Estado do Rio de Janeiro e outra no programa de Ensino de Ciências na UFOP, não havia nenhuma tese até as datas das buscas.

Esse quadro evidencia que a produção do conhecimento tem sido, de forma geral, realizada por diversos programas de pós-graduação. No entanto, há uma discrepância em relação aos programas de pós-graduação em Direito, com uma produção mais vasta em relação a todos os outros programas. Indica, também, a amplitude das afetações que o desastre proporcionou à sociedade brasileira, sendo a maior tragédia socioambiental do Brasil até aquele momento e nos alertando para uma temática que tem sido muito cara ambientalmente e humanamente ao país.

\subsection{Perspectivas para o campo educacional}

A partir dos trabalhos levantados, foram selecionadas três pesquisas, todas de caráter qualitativo. Pela leitura do título das pesquisas acadêmicas, fizemos um recorte inicial selecionando previamente algumas pesquisas. Dentre elas, das que tivemos acesso integralmente, realizamos a leitura dos sumários que permitiu a seleção de três pesquisas que abordam as questões relacionadas ao ensino, educação e os/as jovens que foram atingidos/as no contexto do rompimento da Barragem de Fundão, discussões essas que contribuem no campo educacional. Assim, elaboramos o Quadro 1 , representado a seguir:

\section{Quadro 1 - Tese e dissertações sobre o rompimento da Barragem de Fundão em perspectiva} educacional e publicadas até dezembro de 2019

\begin{tabular}{|c|c|c|c|}
\hline Título & Autor(a)/Ano & Programa & Instituição \\
\hline $\begin{array}{c}\text { As controvérsias nas aulas de biologia a } \\
\text { partir da leitura de jornais impressos: o } \\
\text { desastre ambiental da Samarco }\end{array}$ & 34) Reis, 2018 & $\begin{array}{c}\text { Mestrado Profissional } \\
\text { em Ensino de Ciências }\end{array}$ & $\begin{array}{c}\text { Universidade } \\
\text { Federal de Ouro } \\
\text { Preto }\end{array}$ \\
\hline $\begin{array}{c}\text { "Aprender a ser atingido": educação e } \\
\text { lutas socioambientais diante do } \\
\text { rompimento da barragem de Fundão } \\
\text { (Mariana - MG) no Rio Doce e afluentes }\end{array}$ & 2) Aquino, 2018 & $\begin{array}{c}\text { Mestrado em } \\
\text { Educação }\end{array}$ & $\begin{array}{c}\text { Universidade } \\
\text { Federal do Estado } \\
\text { do Rio de Janeiro }\end{array}$ \\
\hline $\begin{array}{c}\text { Eu quero minha liberdade de volta! } \\
\text { Saúde mental e atenção psicossocial } \\
\text { junto aos adolescentes atingidos pelo } \\
\text { rompimento da Barragem de Fundão }\end{array}$ & 5) Santos, 2018 & Mestrado em Saúde \\
Coletiva & Fundação Oswaldo \\
Cruz
\end{tabular}

Fonte: Elaboração própria a partir de dados da BDTD-IBICT e do Banco de Teses e Dissertações da Capes (2019).

A primeira pesquisa apresentada no Quadro 2 compõe a vasta gama de pesquisas produzidas na Universidade Federal de Ouro Preto, no Mestrado Profissional em Ensino de Ciências, cujo conteúdo propõe refletir como a temática do desastre de Fundão pode ser discutido e problematizado em sala de aula. A dissertação produzida por Reis (2018) tem como objetivo principal analisar os processos de translação nas aulas de Biologia quando utilizada a leitura de matérias de jornais impressos e a produção de reportagens sobre o rompimento da Barragem de Fundão. 
A pesquisa foi embasada nos referenciais teóricos-analíticos de Bruno Latour sobre a Teoria AtorRede (ANT) ao dar ênfase aos jornais - elementos constantemente ligados a uma rede sociomaterial -, em que o autor descreveu e analisou. Assim, procurou entender a aprendizagem como efeitos das redes entre os mais diferentes mediadores. Reis (2018), com base na ANT, considera o engajamento entre humanos e não-humanos (jornal ou as matérias de jornal). Para ele, a oficina com jornais, 0 produto educacional da pesquisa, é uma oportunidade para analisá-los como co-participantes nos processos e relações de aprendizagens dos alunos, isto é, a pesquisa com os jornais, é tida como um Ator-Rede.

Assim, o campo da pesquisa foi resultado do produto educacional (mestrado profissional): uma oficina sobre a produção de jornais com os alunos sobre o tema "desastre socioambiental em Bento Rodrigues". A partir da intervenção realizada pelo autor, foi feita a análise do processo de ensino/aprendizagem de alunos do terceiro ano do Ensino Médio. $O$ autor entende que atividades como as oficinas com jornais podem ser uma oportunidade de mobilização e articulação por parte dos professores aos alunos, para que estes promovam de forma reflexiva e democrática a discussão sobre os entraves e as implicações de uma exploração mineral desmedida e insustentável na Região dos Inconfidentes. A oficina pedagógica ofereceu a oportunidade de aperfeiçoar práticas de leitura e escrita, possibilitando a interação entre os alunos e a troca de experiências, o que pode levar a uma mobilização coletiva muito produtiva.

Após as produções escritas, na etapa final da oficina, os alunos foram convidados a socializar suas produções em um "Jornal Mural". Por essa atividade, os alunos participantes da oficina e toda a comunidade escolar puderam se inteirar sobre os nuances do desastre da Samarco a partir das produções dos alunos. A oficina com jornais, em que a leitura e a produção de textos sobre o evento de Bento Rodrigues foram desenvolvidas, permitiu aos alunos a investigação e o entendimento do desastre em seus mais variados aspectos: científico, humano, social, ambiental e econômico.

Reis (2018) constatou que a oficina com jornais contribuiu para com o ensino/aprendizado dos alunos a partir dos diversos fluxos, circulações e ações descritas ao longo da pesquisa. O autor ressalta, ainda, que, a partir dos resultados, foi possível refletir como as controvérsias foram mobilizadas por meio das notícias de jornais na oficina pedagógica. Reis (2018) acredita que essa atividade se constitui em um produto educacional a ser desenvolvido nas escolas para explorar temas controversos e polêmicos, desenvolvendo nos alunos aspectos relevantes para uma educação cidadã e responsável.

A segunda pesquisa representa a única dissertação advinda de um programa de pós-graduação em Educação, de acordo com os descritores e as datas das buscas. Aquino (2018) parte da problemática instaurada na Bacia do Rio Doce, nos municípios de Maria Ortiz (Colatina - ES) e Mascarenhas (Baixo Guandu - ES), no que tange as ações e atividades lideradas pelo Movimento dos Atingidos por Barragens (MAB) junto aos atingidos da região. Aquino (2018) busca compreender as práticas e processos pedagógicos emergentes das lutas socioambientais ao entender que essas manifestações sociais educam e fomentam a criticidade e a autonomia desses sujeitos pela formação política e socioambiental. Neste aspecto, faz-se o questionamento: de que forma, a partir da apropriação social da educação, os movimentos sociais constroem a formação crítica para a luta coletiva pela emancipação diante de um processo de opressão ambiental?

Na busca da compreensão crítica sobre a realidade imposta aos atingidos após o rompimento da barragem das ações do MAB, a autora utilizou-se do método crítico-dialético para a organização da pesquisa. Assim, o estudo foi realizado sob base qualitativa, utilizando a observação participante para 
a inserção no campo, em contato direto e com trocas de experiências com os sujeitos que integram esse trabalho. Para as informações e coleta de dados, Aquino (2018) utilizou como recurso técnico entrevista semiestruturada, gravação de áudios e fotografias. O método para a coleta dos dados e análise, tanto das entrevistas quanto das visitas aos campos, é o materialista, histórico e dialético.

Com as entrevistas, Aquino (2018) compreendeu a ruptura de pensamento e de concepções da condição de atingido e a necessidade de participação (protagonismo social) nas lutas pela manutenção (resistência) e/ou transformação dos territórios impactados/ameaçados, envolvendo intimamente a relação comunitária do local. Foram criadas, segundo a autora, ações para reunir a comunidade em prol do Rio Doce, convidando, por meio do "boca-boca", para chamar e informar as reuniões e intervenções do movimento na localidade.

Nesse sentido, de acordo com Aquino (2018), o "aprender a ser atingido" está no processo dialógico entre informação, comunicação e educação dentro ou para a militância, em que ambos se complementam no processo de luta por direitos socioambientais, marcado por um processo que envolve diretamente o coletivo impactado no reconhecimento de sua "real" realidade. Além disso, quem aprende com a luta passa, também, a educar outros sujeitos dentro do movimento, à medida que se constrói um olhar social voltado para a tentativa de superação do conflito enfrentado.

A autora propõe, então, uma apropriação social da educação em comunhão com a educação ambiental crítica para a resistência desses grupos ambientalmente atingidos. Aquino (2018) ainda afirma que a educação e a educação ambiental crítica estão intimamente interligadas nesse processo do reconhecer-se atingido; são bases para pensar a autonomia dos sujeitos diante do conflito socioambiental. Dessa forma, na perspectiva da pesquisadora, o intuito foi analisar, a partir da realidade imposta após o desastre, como a educação pode servir como ferramenta de "libertação" (fala de uma entrevistada) para os atingidos da bacia do Rio Doce.

A terceira pesquisa se propõe a analisar a juventude atingida por meio do programa de Saúde Coletiva. O estudo de Santos (2018) tem por objetivo compreender e analisar os impactos psicossociais e as formas de ressignificação dos adolescentes atingidos pelo rompimento da Barragem de Fundão, bem como as ações em saúde mental e atenção psicossocial construídas para esse público, buscando contribuir para futuras intervenções em contextos semelhantes. De acordo com Santos (2018), a revisão de literatura mostra baixo número de publicações sobre o público infantojuvenil em situação de desastre, e os artigos encontrados não aprofundam em aspectos sociais e coletivos da saúde mental de crianças e adolescentes. Além disso, segundo a autora, a maioria dos artigos, protocolos e cartilhas encontrados tratam de desastres naturais, evidenciando uma lacuna sobre a atuação em desastres tecnológicos como o ocorrido em Mariana.

As 300 famílias que foram deslocadas de áreas rurais para a área urbana após o desastre, são violentadas em diversos aspectos, entre eles, na sua condição de saúde e, de acordo com os dados de cadastro da Unidade Básica de Saúde que faz o acompanhamento dos atingidos desde o desastre, são aproximadamente 110 adolescentes, considerando a idade entre 10 e 19 anos. A dissertação também aponta, além da condição da saúde, a importância da educação nesse cenário. Para Santos (2018), a escola se reafirma como um importante espaço para a interação dos adolescentes e integração dessas comunidades. Além de todas as funções pedagógicas, a escola tem uma função de educação social e de cidadania.

A pesquisa foi realizada no período entre 2016 e 2018 nos serviços da Rede de Atenção Psicossocial 
e em duas escolas atingidas pelo desastre no município de Mariana. A pesquisadora utilizou o aporte metodológico da pesquisa qualitativa, através da pesquisa-ação, com o uso das técnicas de observação participante e grupos focais. Os participantes foram adolescentes, profissionais da Rede de Atenção Psicossocial e da educação. Inicialmente, os adolescentes também estavam incluídos como entrevistados, considerando a importância do lugar de fala e protagonismo dos mesmos. Porém, houve dificuldade em relação ao acesso a esses indivíduos dentro das escolas e na organização de um processo de consentimento dos pais. A grande procura das escolas e famílias para o desenvolvimento de atividades e pesquisas pode ser considerada um obstáculo para essa participação, afirma Santos (2018).

Na perspectiva da análise de conteúdo, Santos (2018) construiu as categorias temáticas analíticas: As perdas; Em busca de um lugar; Entre a vulnerabilidade e a potência: buscando formas de ressignificação; A atuação em Saúde Mental e Atenção Psicossocial; e A participação do adolescente nos processos decisórios e de luta por direitos.

As narrativas apontam para dificuldades no processo de adaptação ao novo território e às exigências de ressignificações e de reorganização social e comunitária trazidas por esse novo contexto. Diante de um cenário de tantas perdas e de uma população desterritorializada e vulnerabilizada, a perspectiva de diagnósticos descontextualizados e pouco implicados pode se transformar em mais uma forma de violência a essas populações. Foram desenvolvidas ações e estratégias buscando um olhar ampliado na compreensão dos determinantes sociais em situação de desastres e uma atuação orientada pelo desenvolvimento de potencialidades e da autonomia.

Assim, é preciso considerar que o desastre ainda não cessou e ações a longo prazo precisam continuar sendo desenvolvidas a partir da participação e do protagonismo dos adolescentes. Faz-se importante ressaltar a necessidade de um olhar ampliado na compreensão dos determinantes sociais em situações de desastres para uma atuação orientada pelo desenvolvimento de potencialidades e da autonomia, evitando processos de vitimização, cronificação e adoecimento, salienta Santos (2018).

As dissertações produzidas contribuem com a perspectiva educacional e nos instiga a refletir como esse campo tem a contribuir com a temática do desastre do rompimento da Barragem de Fundão e para tantos outros desastres e tragédias, uma vez que é um fenômeno que se torna cada vez mais comum na vida de muitos brasileiros e brasileiras. É necessário produzir discussões e estratégias que perpassem a problemática do desastre no interior das instituições escolares, das salas de aula e das práticas pedagógicas. Assim, é preciso que

A escola se coloque como uma das mediações que podem contribuir para o projeto de recuperação de territórios impactados pela mineração. Será necessário trazer para a formação escolar a complexidade constituinte da atividade minerária, dos seus impactos, das suas finalidades, do destino da riqueza socialmente produzida e do lugar que esse setor ocupa na produção internacional, nacional, regional e local. Essa tarefa demandará formação continuada, produção de materiais didáticos, comprometimento dos gestores públicos e, principalmente, a necessidade de analisar a relação histórica, e já quase naturalizada, entre empresas mineradoras e instituições públicas, dentre elas a escola (ANTUNES-ROCHA, FANTINEL E HUNZICKER, 2020, p.19).

A instituição escolar, em sua função social, deve ser capaz de pautar o debate em parceria com os estudantes para capacitações de resoluções dos possíveis conflitos futuros. Assim como como pensar reflexões e estratégias de como os(as) estudantes podem colaborar para evitar a ocorrência e/ou a 
vivencia de um desastre, também é preciso refletir como podem ser agentes produtores de mecanismos nas mitigações dos danos para determinados grupo sociais perante os riscos socioambientais e na preservação do meio ambiente nos princípios da educação ambiental, mediante as realidades sociais dos estudantes. E, principalmente como a instituição escolar, os(as) docentes e funcionários(as) podem acolher e restaurar dignidades e reconhecimentos daqueles(as) que vivenciaram eventos trágicos e traumáticos em sua infância e adolescência, uma vez que a vulnerabilidade especial que as crianças apresentam diante do desastre, segundo Pavan (2009), além da característica física de fragilidade, a própria vivência é, na maioria das vezes, uma situação inédita a ser enfrentada, a qual gera angústias, medos e traumas. As crianças de Bento

Vivenciaram este trauma que para sempre estará enlaçado às suas vidas. A pressa para abandonar suas casas, a escola, os quintais, seus animais de estimação, e assistir dos morros o tsunamide lama invadindo todos seus espaços de vida, significa também ter vivenciado este espetáculo aterrorizante que, agora, apresenta-se preso à memória dos seus anos de infância. (FERREIRA; RAHME; VILA REAL, 2017, p.85).

Nesse sentido, Silveira (2017) afirma a necessidade e a importância de se trabalhar a temática do maior desastre ambiental no Brasil por meio das práticas pedagógicas e de abordagens transversais e interdisciplinares.

De acordo com os Parâmetros Curriculares Nacionais (PCN), a problemática referente ao Meio Ambiente atravessa distintas áreas do conhecimento, sendo enriquecedor relacionar o conteúdo das diferentes disciplinas para uma ampla compreensão de assuntos ligados a este tema (SILVEIRA, 2017, p. 81).

Em conjunto com as práticas pedagógicas, é necessário que as reuniões sobre projetos e/ou práticas interdisciplinares ocupem um espaço de destaque no planejamento escolar, segundo Silveira (2017).

Os temas podem ser abordados não só no Ensino Médio, mas também no Ensino Fundamental, uma vez que os temas "Hidrografia" e "Questões Ambientais" são parte integrante do conteúdo programático dessa etapa da Educação Básica, por exemplo, nas disciplinas de Ciências e Geografia, segundo Silveira (2017).

Desse modo, o projeto interdisciplinar é uma prática que deve ser experimentada e debatida no espaço escolar. É enriquecedor para o processo de ensino aprendizagem apreender o objeto de estudo a partir de diferentes perspectivas disciplinares (SILVEIRA, 2017, p. 81).

Assim, é necessário

[...] desenvolver uma "cultura" interdisciplinar na escola, rompendo com o currículo segmentado; criar um espaço institucional para discussão e reflexão sobre a prática pedagógica com a participação de diferentes atores do espaço escolar; e fortalecer as relações interpessoais que possam facilitar a realização destes projetos. Quando a comunidade escolar reconhece que nestes espaços os conteúdos curriculares são debatidos, construídos e reconstruídos, e que há na escola um projeto mais amplo para formar cidadãos críticos e pensantes, significa que esta caminha para uma educação plural, diversa e inclusiva (SILVEIRA, 2017, p. 82).

Silveira (2017) aponta como cada disciplina pode explorar, por exemplo, o tema "Rios do Brasil e Preservação Ambiental" usando recursos como: aulas expositivas, livros didáticos, mapas, maquetes, músicas, jogos, aplicativos, trabalhos de campo, filmes, fotografias, entre outros. "Os recursos didáticos podem promover uma melhoria no processo de ensino-aprendizagem, facilitar a mediação 
entre o conhecimento e o aluno, além de estimular a ludicidade dos mesmos" (SILVEIRA, 2017, p. 82).

Além da relevância das práticas pedagógicas, assinalamos, também, a importância que os movimentos sociais assumem na discussão na problemática dos desastres e como possuem estratégias de atuação no campo educacional. Segundo Valdanha Neto e Jacobi (2020), o MAB tem forte impacto enquanto agente educativo e de mecanismos de ação em uma situação de desastre ambiental no contexto de implantação de duas grandes usinas hidrelétricas na Amazônia. Para isso, o movimento utiliza

[...] diversas estratégias descritas na literatura da Educação Ambiental e do Campo para a efetivação de suas ações. As decorrências foram repercutidas principalmente em duas grandes categorias: a transformação da relação da comunidade consigo mesma (comunidade-comunidade), e da comunidade com o Estado (VALDANHA NETO; JACOBI, 2020, p. 233).

De acordo com Valdanha Neto e Jacobi (2020), um dos lemas do MAB, "informar para mobilizar", expressa o componente educativo organicamente presente no movimento. Segundo os autores, nos contextos de lutas sociais na realidade brasileira, podem ocorrer processos educativos de grande potência para a transformação da relação ambiente-sociedade e, portanto, se trabalhada essa relação em conjunto com a esfera educacional, podem ocorrer mudanças significativas nas perspectivas de gestão ambiental e/ou territorial. Neste contexto, "o MAB é um movimento social que tem a especificidade de centralizar a pauta das consequências de grandes empreendimentos à vida de pessoas (sobretudo camponesas) e ao meio ambiente" (VALDANHA NETO; JACOBI, 2020, p. 236).

Entretanto, os autores ressaltam que a forte influência de um movimento social na relação com a comunidade local em situações de desastres é pouco representada na literatura e necessita "de estudos mais integrados para melhor mensuração de sua relevância e potencialidade de influência em outros casos - resta aí também uma das potencialidades do fortalecimento do diálogo entre a Educação do Campo e a Ambiental" (VALDANHA NETO; JACOBI, 2020, p. 257).

Para a compreensão da relação sujeito-ambiente, segundo Marques e Souza (2019, p. 04),

[...] é importante considerar a percepção ambiental e o que as pessoas sentem em relação ao ambiente em que vivem, assim como as diferentes maneiras de experienciar e interpretar o espaço e lugar, tendo como referência as imagens contidas em sentimentos complexos e até ambivalentes.

Essa relação faz também importante no campo educacional. A percepção dos(as) estudantes sobre o ambiente no qual vivem carrega marcas, estas que se acentuaram após o desastre que atingiu o Rio Doce. De acordo com Marques e Souza (2019), as percepções de estudantes da Educação de Jovens e Adultos (EJA) nas relações subjetivas entre os sujeitos e o Rio Doce carregam marcas da topofobias e desenham as cartografias do medo. A alteração da paisagem também é marcada pelo sentimento de insegurança, de perdas, intensifica as preocupações e transita entre o visível e o invisível.

Compreende-se que os efeitos desse desastre não se restringem ao meio ambiente físico, mas também atingem os diferentes sujeitos e suas manifestações culturais, 0 quadro de vida e do trabalho, a relação com o lugar onde são garantidas as condições adequadas para a reprodução dos laços de existência comunitária. Portanto, o rompimento da barragem e depósito dos sedimentos no rio afetou o ambiente, modificando-o, fazendo emergir também sentimentos de topofobia relacionados às preocupações com a saúde em decorrência do consumo da água potável (MARQUES; SOUZA, 2019, p. 10). 
As autoras apontam que essa preocupação com o consumo da água alcançou também as escolas. Marques e Souza (2019) explicam que os efeitos da destruição do recurso hídrico, o rio, acentuam a desigualdade social, pois não são beneficiados pelo acesso à água de qualidade, que passa a ser mais um custo para a sobrevivência; portanto, a degradação ambiental aprofunda as desigualdades sociais que, por sua vez, refletem-se nas desigualdades educacionais.

A escola é pensada como um espaço que busca desenvolver ações que possam amenizar os sofrimentos dos estudantes e que, portanto, devem garantir instalações em locais seguros para a aprendizagem. Assim, discutir a gestão de risco de desastres nas escolas é extremamente relevante, como abordam as autoras Antunes-Rocha, Fantinel e Hunzicker (2020). Em Bento a escola não era segura e foi completamente destruída pelo mar de lama. Nesse sentido,

\begin{abstract}
Essas situações indicam que a localização em área segura inclui não apenas o edifício da escola, mas também as vias de acesso à mesma, constituindo um desafio para as políticas de educação escolar na região atingida pelo rompimento. $O$ estudo cartográfico da logística de acesso e riscos associados constitui estratégia viável para se enfrentar o desafio. Implica realizar um estudo cartográfico que relacione local de moradia (ou de origem), localização da escola e percurso do transporte com os riscos geológicos, hidrológicos e ambientais a que a comunidade está exposta para ter acesso à escola. Com relação à gestão para a redução de danos provocados pelo desastre, observa-se que, de maneira geral, na situação de calamidade, a escola se torna "visível" porque houve perda de vidas, de sua estrutura física, dos mobiliários e recursos pedagógicos; e, ainda, porque as vias de acesso foram obstruídas ou o espaço e instalações da escola foram transformados em local de abrigo (ANTUNESROCHA, FANTINEL E HUNZICKER, 2020, p.19).
\end{abstract}

Pensar nas desigualdades que foram evidenciadas com o desastre e nas vidas que foram afetadas é pensar, também, nas vivências desses jovens, adolescentes e adultos no interior da instituição escolar. O debate está intimamente ligado, pois vislumbrar uma educação que favoreça a redução das desigualdades, que seja pública e de qualidade é situar as vivências dos estudantes e repensar estratégias de fortalecimento da permanência e de formação crítica cidadã contextualizadas. Ou seja, é necessário refletir "como a formação escolar poderia contribuir para a construção de um projeto que sinalize para perspectivas de futuro (ANTUNES-ROCHA, FANTINEL E HUNZICKER, 2020, p.19).

\title{
4. CONSIDERAÇÕES FINAIS
}

Com o estado do conhecimento, compreendemos a produção dos discursos acadêmicos acerca do rompimento da Barragem de Fundão e os desdobramentos, principalmente em relação à população atingida. A escassez de estudos provenientes de programas de pós-graduação em Educação ou com foco na instituição escolar e na juventude atingida indica a (falta de) preocupação e atenção que os(as) pesquisadores(as) dão à temática e mostra que alguns temas são quase totalmente silenciados. Isto é, a ausência de pesquisas que contribuam diretamente para o campo educacional e a baixa produção nas Ciências Humanas e Sociais, com exceção dos programas de pós-graduação em Direito, estão nitidamente presentes neste estado do conhecimento. Nesse sentido, faz-se necessário fortalecer o campo de estudos acerca dos desastres para além de um evento de grande proporcionalidade midiática bem como pensar estrategicamente sobre como o campo educacional pode contribuir na discussão dos assuntos relativos aos desastres.

As pesquisas acadêmicas indicadas pelo Quadro 2 discutem a problemática instaurada após 0 
rompimento da Barragem de Fundão no campo das relações sociais e humanas ligadas ao campo educacional. Os(as) autores(as) desse grupo ressaltam as perdas, o sofrimento e as lutas dos(as) atingidos(as) em uma perspectiva ampla dos objetos de estudos investigados e salientam a importância de estudos que reflitam, de forma crítica, o desastre. Na realidade, essas pesquisas acabam não só se referindo à Barragem de Fundão, mas também ao contexto histórico desigual e vulnerável na qual a problemática se insere.

As investigações valeram-se de estudos que fazem a análise de uma oficina pedagógica, estudo de história de vida e estudo de pesquisa-ação. Outro aspecto refere-se às técnicas utilizadas nas pesquisas: entrevistas, análise de documentos, observação e grupo focal. Por meio dos dados, percebemos que as produções teóricas acadêmicas confirmam a grave violação dos direitos humanos cometida pelas empresas Samarco, Vale e BHP Billiton.

O aporte teórico utilizado pelos(as) pesquisadores(as) baseou-se em: Valencio (2009; 2010; 2011; 2012; 2014; 2016), Latour (1988; 1994; 2000; 2002; 2004; 2005; 2012), Zhouri (2016), Coutinho (1995; 2009; 2014; 2017), Freire (2011; 2014; 2016), Loureiro (2002; 2004; 2006; 2011; 2012) e Marx (1983; 1998; 2008). Os obstáculos para trabalhar com o tema tornam-se visíveis em algumas pesquisas, principalmente em relação ao acesso aos adolescentes dentro das escolas e à organização do processo de consentimento dos pais.

As pesquisas encontradas neste levantamento demonstram como o evento do rompimento da Barragem de Fundão contém vários aspectos que possibilitam e/ou exigem estudos aprofundados. $\mathrm{A}$ temática do desastre pode ser discutida e problematizada em sala de aula a partir de oficina com jornais, em processos e relações de aprendizagens dos(as) alunos(as) e uma oportunidade de mobilização e articulação por parte dos(as) professores(as) e, portanto, desenvolver aspectos relevantes para uma educação cidadã.

Além disso, evidenciam como as práticas e processos pedagógicos emergentes das lutas socioambientais educam e fomentam a criticidade e a autonomia desses sujeitos pela formação política e socioambiental. Nesse sentido, ajudam a compreender como a educação e a educação ambiental crítica estão intimamente interligadas nesse processo do reconhecer-se atingido e, portanto, como a educação pode servir como ferramenta de "libertação". Por fim, uma das dissertações demonstrou, através da revisão de literatura, o baixo número de publicações sobre o público infanto-juvenil em situação de desastre. A pesquisa também apontou que, além da condição da saúde, a educação também assume um lugar importante nesse cenário de perdas e danos.

\section{REFERÊNCIAS}

ALEGRETTI, Laís. Lama que vazou de barragem deve ter chegado ao sul da Bahia, diz Ibama. Disponivel em: http://g1.globo.com/minas-gerais/desastre-ambiental-emmariana/noticia/2016/01/lama-que-vazou-de-barragem-pode-ter-chegado-ao-sul-da-bahia-dizibama.html. Acesso em: 27 de nov. 2020.

ANTUNES-ROCHA, Maria Isabel; FANTINEL, Lúcia Maria; HUNZICKER, Adriane Cristina de Melo. O rompimento da barragem B1 da mina córrego do feijão e os desafios para a educação. Revista Ciência \& Cultura. Ano 72, n.2, abril/maio/junho, 2020.

AQUINO, Mahalia Gomes de Carvalho. "Aprender a ser atingido": educação e lutas socioambientais diante do rompimento da barragem de Fundão (Mariana - MG) no rio Doce e 
afluentes. 2018. 113f, Dissertação (Mestrado em Educação) - Universidade Federal do Estado do Rio de Janeiro. Rio de Janeiro: UFRJ, 2018.

DAMASIO, Kevin. Lama tóxica da barragem de Mariana contaminou corais de Abrolhos, diz novo estudo. Disponível em:https://www.nationalgeographicbrasil.com/meioambiente/2019/02/lama-toxica-poluicao-barragem-fundao-samarco-mariana-abrolhos Acesso em: 27 de nov. 2020.

DIEGUEZ, Consuelo. A onda. Piauí 118, 10 jul. 2016. Disponível em: https://piaui.folha.uol.com.br/materia/a-onda-de-marianal. Acesso em: 14 jun. 2019.

FERREIRA, Carla Mercês da Rocha Jatobá; RAHME, Mônica Maria Farid; VILA REAL, Fernanda Carvalho de Faria. A barragem de Fundão - seu rompimento, as vidas e a mídia - algumas considerações (Mariana, Minas Gerais, Brasil). Heurística revista digital de história de la educación. n.20. Enero - diciembre, 2017.

FERREIRA, Norma Sandra de Almeida. As pesquisas denominadas "Estado da Arte". Educação \& Sociedade, ano XXIII, n. 79, ago. 2002.

MARCHEZINI, Victor. As ciências sociais nos desastres: um campo de pesquisa em construção. BIB, São Paulo, n.83, 2018, pp.43-72.

MARQUES, Gilda de Melo; SOUZA, Maria Celeste Reis Fernandes de. Percepção de estudantes jovens e adultos sobre o Rio Doce: cartografias do medo. Ambiente \& Sociedade. São Paulo, v. 22, 2019.

OLIVEIRA, Marcelo. Mariana vira $1^{0}$ crime ambiental apontado como violação de direitos humanos. Geledés, 19 dez. 2019. Disponível em: https://www.geledes.org.br/mariana-vira-10-crimeambiental-apontado-como-violacao-de-direitos-humanos/. Acesso em: 20 dez. 2019.

PAVAN, Beatriz J. C. O olhar da criança sobre o desastre: uma análise baseada em desenhos. In: VALENCIO, Norma et al. (Orgs.). Sociologia dos Desastres: construção, interfaces e perspectivas no Brasil. São Carlos: RiMa, 2009.

REIS, Alexsandro Luiz dos. As controvérsias nas aulas de Biologia a partir da leitura de jornais impressos: o desastre ambiental da Samarco. 2018. 103f. Dissertação (Mestrado Profissional em Ensino de Ciências) - Universidade Federal de Ouro Preto. Ouro Preto: UFOP, 2018.

ROMANOWSKI, Joana Paulin; ENS, Romilda Teodora. As pesquisas denominadas do tipo "estado da arte" em educação. Diálogo Educ. Curitiba, v. 6, n. 19, p. 37-50, set./dez. 2006.

SANTOS, Marcela Alves de Lima. Eu quero minha liberdade de volta! Saúde mental e atenção psicossocial junto aos adolescentes atingidos pelo rompimento da barragem de Fundão. 2018. 90f. Dissertação (Mestrado em Saúde Coletivo) - Fundação Oswaldo Cruz. Belo Horizonte: Fundação Oswaldo Cruz, 2018.

SERRA, Cristina. Tragédia em Mariana: a história do maior desastre ambiental do Brasil. $1^{\text {a }}$ ed. Rio de Janeiro: Record, 2018.

SILVEIRA, Patrícia Gomes da. O espaço escolar e o desastre ambiental no vale do Rio Doce: projeto interdisciplinar e importância da Geografia. Giramundo. Rio de Janeiro, v. 4, n. 7, p. 79-87, jan./jun. 2017. 
REZENDE, Elcio; SILVA, Victor Vartuli Cordeiro e. De Mariana a Brumadinho: a efetividade da responsabilidade civil ambiental para a adoção das medidas de evacuação. Revista do Direito. Santa Cruz do Sul, v. 1, n. 57, p. 160-181, jan/abr. 2019.

VALDANHA NETO, Diógenes; JACOBI, Pedro Roberto. O movimento dos atingidos por barragens e o enfrentamento de desastre ambiental: uma aproximação prática da educação ambiental e do campo. Ambiente e Educação - Revista de educação Ambiental. Porto Alegre, v. 25, n. 2, 2020.

VALENCIO, Norma. Da morte da Quimera à procura do Pégaso: a importância da interpretação sociológica na análise do fenômeno denominado desastre. In: VALENCIO, Norma; SIENA, Mariana; MARCHEZINI, Victor; GONÇALVES, Juliano Costa. Sociologia dos Desastres: construção, interfaces e perspectivas no Brasil. São Carlos: Rima Editora, 2009, p.3-18.

Submissão: 20/10/2020

Aceito: 02/12/2020 